\title{
As abelhas e seu serviço ecossistêmico de polinização
}

\section{Deise Barbosa Barbosa \\ Universidade Estadual do Rio Grande do Sul, Unidade Universitária em Tapes. \\ Eliane Fátima Crupinski \\ Rosângela Nunes Silveira \\ Daniela Cristina Hass Limberger \\ Tapes, RS, Brasil. \\ E-mails: deisebb@yahoo.com.br elianecrupinski@yahoo.com.br rosangela-nunes@uergs.edu.br daniela-limberger@uergs.edu.br}

Recebido em: 15 mar. 2017. Revisado em: 21 mar. 2017 Aceito: 02 abr. 2017.

DOI: http://dx.doi.org/10.21674/2448-0479.34.694-703

\section{Resumo}

Com os avanços da agricultura, o desflorestamento, o desenvolvimento urbano e demais atividades antrópicas, a biodiversidade está ameaçada. As populações de polinizadores naturais também diminuem, por não encontrar mais recursos suficientes para alimentar-se e nidificar-se. Dessa forma, com esta revisão narrativa, buscou-se uma reflexão sobre a presteza das abelhas em seus serviços ecossistêmicos. A polinização é um serviço ecossistêmico que tanto os sistemas naturais como agrícolas dependem, mas que não tem ganho a devida importância econômica. As abelhas são os principais agentes polinizadores, prestando um serviço ecossistêmico extremamente importante, pois além de contribuírem com o meio ambiente auxiliando na disseminação das plantas, garantindo a variação 
genética importante para o desenvolvimento das espécies, são produtoras de mel. A presença de abelhas indica qualidade ambiental e, portanto a perda deste inseto ameaça inclusive a saúde ambiental dos ecossistemas existentes.

Palavras-chave: Serviços ecossistêmicos. Abelhas. Polinização.

\section{Introdução}

As abelhas são consideradas de extrema importância para a manutenção da vida no planeta. São elas responsáveis pela polinização de ecossistemas agrícolas e naturais. Apesar da relevância, elas estão em declínio por causa das diversas ações antrópicas que destroem seus ninhos, principalmente, por questões econômicas. A perda de uma espécie de abelha polinizadora pode reduzir ou mesmo extinguir espécies vegetais. É necessário utilizar alternativas que atendam aos interesses sociais, econômicos e, principalmente, ambientais para a sua preservação.

$\mathrm{Na}$ maioria dos ecossistemas mundiais, as abelhas são os principais polinizadores (BIESMEIJER; SLAA, 2006). Estudos sobre a ação das abelhas no meio ambiente evidenciam a extraordinária contribuição desses insetos na preservação da vida vegetal e também na manutenção da variabilidade genética (NOGUEIRACOUTO, 1998).

Entretanto, devido à redução das fontes de alimento e de locais de nidificação, à ocupação intensiva das terras e ao uso de defensivos agrícolas, as populações de abelhas silvestres têm sido reduzidas drasticamente, colocando em risco todo o bioma em que 
vivem. Uma das dificuldades em se promover a conservação das abelhas é a falta de conhecimento sobre as mesmas. Dessa forma, buscou-se através desta revisão narrativa, realizar uma reflexão, verificando a explanação de diversos autores, alertando sobre esta temática.

\section{Metodologia}

Realizou-se uma pesquisa bibliográfica para buscar dados e informações a respeito do tema. Foram selecionados artigos científicos, livros, teses e dissertações consultados entre os meses de outubro de 2016 e janeiro de 2017, através das palavras chaves: serviços ecossistêmicos e abelhas. Após seleção entre os 349 referenciais encontrados, construiu-se uma revisão narrativa de forma a refletir sobre o serviço ecossistêmico prestado pelas abelhas.

\section{Referencial teórico}

De acordo com FAO (2004), a polinização é uma etapa fundamental do processo reprodutivo das plantas que, por sua vez, constituem os produtores primários nos ecossistemas terrestres e responsáveis diretos por muitos dos serviços prestados pelos ecossistemas, como sequestro de carbono, prevenção da erosão dos solos, fixação de nitrogênio, manutenção dos lençóis freáticos, absorção de gases do efeito estufa e fornecedores de alimento e habitat para a maioria das formas de vida aquática e terrestre. Além do que os serviços ecossistêmicos da polinização correspondem a cer- 
ca de $10 \%$ do PIB agrícola, representando a incrível cifra superior a U\$ 200 bilhões/ ano, no mundo.

Assim, a polinização mostra-se como um importante mecanismo ecológico frente aos enormes serviços ambientais que prestam. Esses serviços ambientais, são chamados de serviços ecossistêmicos, sendo base para a sobrevivência dos organismos no planeta e fundamentais para a o bem estar humano. Também são considerados como um capital natural de valor incalculável frente aos seus benefícios e consistem em um estoque de materiais e informações que estão disponíveis aos seres humanos para serem usados e transformados em outros materiais para melhorar a vida humana (COSTA; OLIVEIRA, 2014).

Para Nates-Parra (2005), "aproximadamente metade dos animais que polinizam as plantas tropicais são abelhas". Dentre as diversas espécies de abelhas até agora identificadas, as abelhas indígenas sem ferrão (Meliponinae) são responsáveis pela polinização de até $90 \%$ da flora nativa do Brasil (KERR et al., 1996).

As abelhas formam um grupo diverso e numeroso, compreendendo mais de 20 mil espécies no mundo. No Brasil, estima-se a existência de mais de 3.000 espécies diferentes, mas apenas pouco mais de 400 estão catalogadas. As espécies nativas são os meliponíneos, são as abelhas sem ferrão, que compõem a grande maioria das espécies de abelhas de nosso país.

A mais conhecida é a Apis Mellifera, conhecidas como as abelhas do mel ou africanizadas, são abelhas exóticas, híbridos do cruzamento de abelhas da Europa e da África, e são as mais utilizadas na apicultura, sendo estas abelhas com ferrão. Existe também o grupo das abelhas solitárias e ainda as abelhas do gênero Bombus, popularmente conhecidas como mamangavas. 
As abelhas tanto adultas, quanto suas larvas e pupas, alimentam-se exclusivamente de recursos florais. Segundo Roberto et al. (2015), as abelhas dependem das plantas para a sobrevivência, as adultas se alimentam principalmente de néctar, mas as larvas das abelhas, na maior parte das espécies, são alimentadas com uma mistura de pólen e néctar.

Por isso, para suprir sua necessidade alimentar e de sobrevivência, as abelhas visitam uma grande variedade de flores, colhendo o pólen (fonte de proteína) e o néctar (para a produção do mel). $\mathrm{Na}$ polinização quando uma abelha visita uma flor, seu corpo pode ficar coberto de grãos de pólen e ela voando para outra flor, deposita os grãos de pólen sobre o estigma dessa outra flor e então ocorre a polinização (ROBERTO et al., 2015). Esta atividade é, portanto, uma ação involuntária dos polinizadores, mas essencial à vida das plantas, que se utilizam de cheiros, cores e sabores para atraí-los. Entorno de $85 \%$ das plantas com flores presentes nas matas e florestas da natureza, dependem, em algum momento, dos polinizadores para se reproduzirem.

As abelhas, desta forma, se beneficiam pelo alimento que vem das flores, as plantas por continuarem sua reprodução e o agricultor por ter os seus cultivares de produção bem polinizados garantindo frutos de melhor qualidade, sendo maiores, mais pesados e agregando maior valores nestes produtos, além da produção de mel (SOUZA et al, 2004).

A presença destes insetos indica qualidade ambiental, e para tanto há de se atentar para a preservação das abelhas, que devido às mudanças climáticas vem sofrendo impactos que podem levar ao seu desaparecimento.

Quanto ao desaparecimento das abelhas, o relato de Carlson no livro Primavera Silenciosa sobre o uso dos pesticidas agrícolas 
trouxe a necessidade de se respeitar o ecossistema em que vivemos. A preocupação com o meio ambiente promoveu inúmeros movimentos, mas teve seu marco em 1972 na Conferência Mundial das Nações Unidas sobre o Meio Ambiente Humano, onde se estabeleceu o conceito de desenvolvimento sustentável como sendo o desenvolvimento que atende as necessidades atuais sem comprometer a habilidade das futuras gerações de atender suas próprias necessidades. De lá pra cá muitos foram os avanços na tentativa de regular a relação social - econômica - ambiental. A verdade é que por maiores que tenham sido os avanços na preservação dos biomas e controle no uso de químicos, esta prática de degradação do meio ambiente é atual e as consequências muito preocupantes.

Apesar de não termos pesquisa com dados específicos, sabemos que as abelhas estão em processo gradativo de ameaça a extinção. As pesquisas são no sentido da contaminação do meio ambiente por agrotóxicos, em que existem dados mostrando que $50 \%$ do pólen coletado no Brasil possuem traços de agrotóxicos. Muitos são os efeitos dos pesticidas nas abelhas, se o contato for direto ela morre, no entanto, se estiver no pólen ela carrega para as colônias e compromete a sobrevivência das mesmas.

Cox e Wilson (1984) verificaram que abelhas expostas à Permetrina perdem sua capacidade de orientação e podem não voltar à colônia, além de apresentarem graves distúrbios de comportamento que afetam a capacidade de forrageamento. Daí o termo "desaparecimento das Abelhas", efeito do uso dos pesticidas.

Rocha (2012) aponta que alguns comportamentos das abeIhas podem fornecer indícios de que a colmeia está sendo afetada por substâncias tóxicas, tais como: grande número de abelhas mortas nas proximidades das colônias; decréscimo na produção de progênie; diminuição da atividade de forrageamento; irritabilidade ex- 
cessiva; autolimpeza excessiva; incapacidade de substituição da rainha; mortalidade das larvas; má formação das larvas.

Kerr et al. (2005), relataram os impactos que causa a extinção desta espécie:

- Desmatamentos - Quase a totalidade de 300 a 350 espécies de abelhas vivem em ocos de árvores, que são destruídas com os desmatamentos.

- Queimadas - Rainhas fecundadas têm abdomens desenvolvidos, pesando muito não conseguindo voar; $2 \%$ a $3 \%$ das espécies fazem ninhos subterrâneos superficiais, sendo mortas facilmente.

- Ação dos meleiros - Após coleta do mel, quando em habitat natural, a cria é deixada no chão sendo posteriormente destruída pelas formigas.

- Ação das serrarias - Retiram da floresta árvores idosas, que geralmente tem ocos adequados para serem ocupados por novos enxames.

- Fragmentação - Fragmentos pequenos não permitem a variabilidade genética.

- Inseticidas - Os usos em áreas agrícolas afetam meliponários e áreas de mata próximas aos cultivos.

- Fome - Destruição de ninho com a finalidade de matar a fome.

\section{Resultados e discussão}

A degradação de todo o fluxo de serviços ecossistêmicos têm importantes impactos no bem-estar de todos, visto a interdependência complexa e não-linear do homem aos serviços ecossistêmicos. Ressalta-se que, tornando-se escasso um serviço Rev. Elet. Cient. UERGS, v. 3, n. 4 (Número Especial), p. 694-703, 2017 
ecossistêmico ocorre um decréscimo em seu fluxo, reduzindo o bem-estar do homem.

Conhecendo-se estudos realizados e as necessidades da sociedade em relação à polinização e aos polinizadores, sendo este um elemento não só de estabilidade e equilíbrio ecológico, mas também importante na gestão dos recursos vegetais cultiváveis mostra-se fundamental criar panoramas que possibilitem potencializar seus serviços e desenvolver técnicas de conservação e manejo adequado, além da representação de espaços geográficos e estimativas de mudanças climáticas.

Nessa narrativa identificou-se o grande benefício que os polinizadores fornecem para a estabilidade dos ambientes e a suas relações com os cultivos agrícolas. Muitas informações, ainda precisam ser esclarecidas e descritos todos os fluxos e dependência humana para os cultivos e suas interações planta-polinizador, para que seja possível valorar esse importante serviço ecossistêmico para a humanidade.

\section{Conclusão}

Conhecendo o comportamento da espécie, podemos concluir que as abelhas são essenciais para a vida humana e vegetal. $O$ risco de extinção de alimentos como do tomate, café, manga, coco, laranja, melão, goiaba, melancia, pimentão, maçã, chuchu, jabuticaba, canola, urucum, berinjela, girassol, abacate, pepino, pêssego, carambola, entre outros, que dependem do serviço ecossistêmico de polinização das abelhas, nos coloca em alerta.

É necessário que políticas de uso de agrotóxicos na agricultura no Brasil sejam revistas e as penalidades efetivadas. Assim como Rev. Elet. Cient. UERGS, v. 3, n. 4 (Número Especial), p. 694-703, 2017 
práticas de desmatamento e queimadas, sejam fiscalizadas e autuadas se necessário.

Países desenvolvidos já começaram esta corrida, com o objetivo de preservação de espécies e biomas. No Brasil só a educação ambiental não conseguirá retorno na proporção necessária para mitigar os danos deste comportamento devastador para a população das abelhas, o governo precisa ser atuante com suas políticas e fiscalização. Estas revisões científicas podem alertar outras partes interessadas fora do universo acadêmico. Dessa forma, estudos devem ser disseminados, alcançando outros setores da sociedade tais como agricultores e gestores contribuindo para a valoração da polinização.

\section{Referências}

BIESMEIJER, J.C.; SLAA, E.J. The structure of eusocial bee assemblages in Brazil. Apidologie, n.37, p. 240-258, 2006.

COSTA, C.C.de A.; OLIVEIRA, F.L. Polinização: serviços ecossistêmicos e o seu uso na agricultura. Revista Verde de Agroecologia e Desenvolvimento Sustentável, v. 8, n. 3, p.1-10, 2014.

COX, R. L.; WILSON, W. T. Effects of permethrin on the behavior of individually tagged honey bees, Apis mellifera L. (Hymenoptera:Apidae). Environmental Entomology, v. 13, p. 375-378, 1984.

FAO. Conservation and management of pollinators for sustainable agriculture - the international response. In: FREITAS, B.M.; PEREIRA, J.O.P. Solitary bees: conservation, rearing and management for pollination, 2004. p. 19-25.

FREITAS, B.M. As abelhas como agentes polinizadores na produção de alimentos e conservação de recursos florais. Anais de SIM- 
PÓSIOS DA 43a REUNIÃO ANUAL da SBZ - João Pessoa, PB. 2006.

KERR W.K., CARVALHO G.A., NASCIMENTO V.A. Abelha uruçu: biologia, manejo e conservação. Paracatu: Acangaú, 1996.

KERR W.E., CARVALHO G.A., SILVA A.C., ASSIS M.G.P. Aspectos pouco mencionados da biodiversidade amazônica. Mensagem doce. n. $80,2005$.

NATES-PARRA, G. Abejas silvestres y polinización. Manejo Integrado de Plagas y Agroecología. Costa Rica, v. 75, p. 7-20, 2005.

NOGUEIRA-COUTO, R.H. As abelhas na manutenção da biodiversidade e geração de rendas. In: CONGRESSO BRASILEIRO DE APICULTURA, 12, 1998, Salvador-BA. Anais... Salvador: 1998, p. 101.

ROBERTO, G.B.P. et al. As abelhas polinizadoras nas propriedades rurais. Rio de Janeiro: Funbio, 2015.

ROCHA, M.C.L.S.A. Efeitos dos agrotóxicos sobre as abelhas silvestres no Brasil: proposta metodológica de acompanhamento. Brasília: Ibama, 2012.

SANTOS, A. B. Abelhas nativas: polinizadores em declínio. Natureza on line, v. 8, n.3, 103-106, 2010.

SOUZA, R. C. da S. et al. Valor nutricional do mel e pólen de abelhas sem ferrão da região amazônica. Acta Amazonica, 2004. 